\title{
Modelagem matemática do processo de hidrólise da produção de etanol por meio do mecanismo enzimático de Michaelis-Menten
}

\author{
Mathematical modeling of the processs of hydrolysis of \\ ethanol production through the enzymatic \\ mechanism of Michaelis-Menten
}

\author{
Mattheus Lustosa de Melo Machado ${ }^{1}$ \\ (1) http://orcid.org/0000-0003-0324-883X
}

\author{
Ranon de Souza Gomes ${ }^{2}$ \\ (1) http://orcid.org/0000-0001-8932-4834
}

\begin{abstract}
Resumo: Este artigo tem como objetivo modelar o processo de hidrólise da produção de etanol que se faz a partir de fontes vegetais como a batata, o milho, a mandioca e a cana-de-açúcar. Utilizamos o mecanismo enzimático proposto por Michaelis-Menten para desenvolver um modelo matemático formado por um sistema de equações diferenciais não lineares. Com aplicação do método, obtivemos duas soluções, uma solução analítica obtida extraindo relações de conservação de massa referente as espécies químicas envolvidas na reação enzimática e admitindo uma hipótese de estado estacionário, outra numérica obtida através do método numérico de Runge-Kutta Clássico de $4^{a}$ ordem. Os resultados obtidos estão de acordo com dados encontrados na literatura para diferentes concentrações das espécies envolvidas no processo de hidrólise. Tais resultados nos permitem uma melhor análise e otimização do processo de produção do etanol, visto que a hidrólise enzimática apresenta uma vantagem de sustentabilidade. Além disso, não provoca a quebra de moléculas da enzima por não exigir altas temperaturas e pressão. O etanol é uma alternativa para diminuir problemas ambientais e energéticos no mundo, considerando a escassez e alta dos preços dos combustíveis fósseis, além da poluição causada por eles. Logo, a produção de bioetanol ganha grande interesse no mercado nacional.

Palavras-chave: Modelagem matemática, Processo de hidrólise, Produção de etanol.
\end{abstract}

Abstract: This article aimed to model the process of hydrolysis of ethanol production that made from plant sources such as potato, maize, cassava, and sugarcane. We used the enzymatic mechanism proposed by Michaelis-Menten to develop a mathematical model formed by a system of non-linear differential equations. With the application of the method, we obtained two solutions, an analytical solution obtained by extracting relationships of mass conservation referring to the chemical species involved in the enzymatic reaction and admitting a stationary state hypothesis, another numerical obtained through the numerical method of Runge-Kutta Classic 4th order. The results obtained are in agreement with data found in the literature for different concentrations of the species involved in the hydrolysis process. These results allow us to analyze better, and optimization of the ethanol production process, since enzymatic hydrolysis presents a sustainability advantage. Besides, it does not cause the enzyme molecules to break because it does not require high temperatures and pressure. Ethanol is an alternative to reduce environmental and energy problems in the world, considering the scarcity and high prices of fossil fuels, in addition to the pollution caused by them. Therefore, the production of bioethanol gains a keen interest in the domestic market.

Keywords: Mathematical modelling, Hydrolysis process, Ethanol production.

\footnotetext{
${ }^{1}$ Estudante do Curso de Graduação em Matemática, Universidade Federal do Amapá, Departamento de Ciências Exatas e Tecnológicas. E-mail: mattheuslustosa07@gmail.com.

${ }^{2}$ Doutor em Matemática Aplicada pela Universidade Federal do Rio Grande do Sul e professor substituto da Universidade Federal do Amapá, Departamento de Ciências Exatas e Tecnológicas, Curso de Graduação em Matemática. E-mail: ranon@unifap.br.
} 


\section{INTRODUÇÃO}

Etanol, álcool ou álcool etílico são um mesmo composto orgânico da fórmula $\mathrm{C}_{2} \mathrm{H}_{6} \mathrm{O}$, obtido através da fermentação de açucares, hidratação do etileno ou redução do acetaldeído. A evolução da produção do etanol no Brasil se deu com a crise do preço do petróleo em 1973, após o fim da Segunda Guerra Mundial, iniciando em 1975 com o programa Proálcool onde o objetivo era estimular a produção do álcool oriundo da cana-de-açúcar, milho ou qualquer outro insumo, diminuindo a dependência das importações de petróleo, atendendo a demanda do mercado interno e externo e as necessidades da política de combustíveis automotivos (CRUZ; GUERREIRO; RAIHER, 2012).

O etanol tem sido considerado uma alternativa para diminuir problemas ambientais e energéticos no mundo em razão da escassez e alta dos preços dos combustíveis fósseis e da poluição por eles causada. Comparado aos combustíveis fósseis, o etanol apresenta as vantagens de ser uma fonte renovável de energia, e de contribuir para a redução das emissões de dióxido de carbono (PACHECO, 2011).

O cenário energético atual tem estimulado o interesse de pesquisa ativa em não petrolíferos, combustíveis renováveis e não poluentes (SINGHANIA, PARAMESWARAN, PANDEY, 2009), por serem a única fonte alternativa de energia para o futuro previsível e ainda formam a base do desenvolvimento sustentável em termos socioeconômicos e ambientais. O Brasil encontra-se em uma posição favorável no que se refere a produção de etanol, por apresentar vantagens na tecnologia de produção, possibilidade de liderança no mercado de biocombustíveis sem ampliar área desmatada ou reduzir a área destinada à produção de alimentos, diversidade de matérias-primas em diferentes biomas.

Para a produção do etanol, é necessário extrair açúcares de outras substancias, já que não é um produto encontrado de forma pura na natureza. Podemos obtê-lo em um processo de fermentação através de moléculas de açúcar encontradas em diversas fontes vegetais. De acordo com a matéria prima, o processo pode se tornar mais simples ou complexo. Para produzi-lo a partir de caldo de cana-de-açúcar ou beterraba, será necessário somente uma moagem para extração de açúcares para a fermentação.

Após a eliminação de impurezas, inicia-se a fermentação onde é misturado com um fermento com leveduras, sendo a Saccharomyces Cerevisia a mais comum utilizada, onde as moléculas de glicose se quebram produzindo etanol e gás carbônico. Já em processos de produção que utilizam o amido advindo de grãos, como o milho, antes da fermentação é preciso realizar uma etapa de sacarificação. Nesta etapa, o amido é geleificado por cozimento para que os grânulos de amido estejam sujeitos à ação das enzimas e submetido à hidrólise enzimática para formar monômeros de glicose, que assim podem ser fermentados por micro-organismos.

Nesse trabalho é evidenciado a atenção nos passos iniciais deste processo, dando ênfase ao processo de produção que utilizam amido advindo de grãos, onde é realizada a hidrólise enzimática. Vamos modelar a reação enzimática, representada pela cinética clássica de Michaelis-Menten, e obter uma solução analítica e numérica do sistema não linear de Equações Diferenciais Ordinárias. 


\section{MÉTODO E MATERIAL}

Com o objetivo de modelar e investigar as características cinéticas decorrentes do processo de hidrólise na produção de Etanol, foram coletados dados por meio de uma pesquisa bibliográfica para reunir as informações que servirão de base para a construção da investigação proposta.

Na primeira etapa, foi realizado um estudo referente a hidrólise enzimática na produção de Etanol, compreendendo a reação enzimática representada pelo mecanismo de Michaelis-Menten. Partes do material foram coletados da sétima edição do livro Bioquímica, escrito por Berg, Tymocsko e Stryer (2014) e do artigo de referência Modeling the bydrolysis process of the bioethanol production, escrito por Gomes, Carpes, Lorenzzetti e Bortoli (2012).

Na segunda etapa, com base no livro Mathematical Biology: I. an introduction, escrito por Murray (2002) e sua abordagem sobre a cinética da reação enzimática, modelamos os mecanismos de Michaelis obtendo um sistema de equações diferenciais não lineares. A resolução do Sistema se deu numericamente pelo Método de Runge-Kutta Clássico de $4^{a}$ ordem e analiticamente por uma redução baseadas em escalas de tempo envolvidas na reação enzimática.

\section{MODELAGEM MATEMÁTICA}

\subsection{Cinética enzimática}

O conhecimento da cinética de uma reação é importante para a caracterização da respectiva enzima porque oferece pistas sobre o seu comportamento e permite prever o seu mecanismo de ação. As enzimas reúnem os substratos, que são ligados a um sítio ativo, proporcionando o aumento de velocidade característico da ação da enzima, formando um complexo de enzima-substrato ES.

O grau de formação do produto é determinado em função do tempo para uma série de concentrações do substrato. A quantidade de produto formado aumenta com o passar do tempo, embora finalmente seja alcançado um momento em que não ocorre nenhuma mudança efetiva do substrato ou produto. A enzima ainda estará convertendo ativamente o substrato em produto, e vice-versa, porém o equilíbrio da reação terá sido alcançado (BERG; TYMOCZKO; STRYER, 2014).

A velocidade de uma reação catalisada enzimaticamente aumenta de modo linear à medida que aumenta a concentração de substrato, até que seja estabilizada, como apresenta a Gráfico 1. Podemos definir a velocidade de catálise $V_{0}$ como o número de moles de produto formado por segundo, quando a reação está apenas começando, ou seja, quando $t \approx 0$ (BERG; TYMOCZKO; STRYER, 2014). Dessa forma, a saturação da enzima com elevadas concentrações de substrato conduz à independência da velocidade da reação relativamente à concentração de substrato. 
Gráfico 1: Cinética de Michaelis-Menten

Chart 1: Michaelis-Menten Kinetics

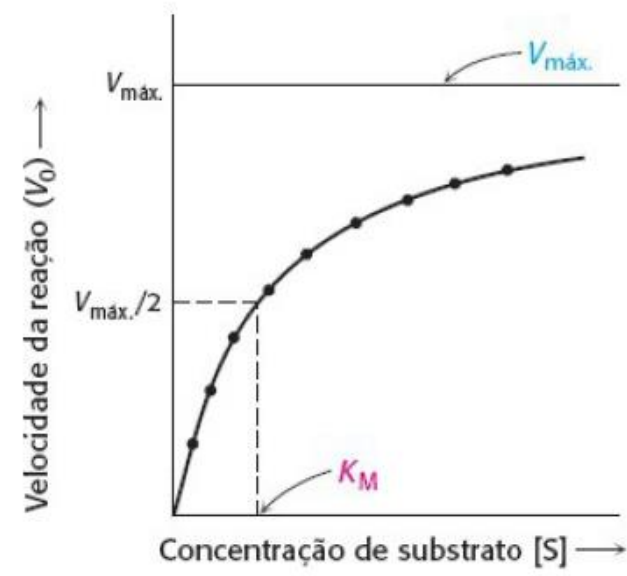

Fonte: BERG; TYMOCZKO; STRYER, 2014.

\subsection{O modelo de Michaelis-Menten}

O estudo da cinética enzimática começou em 1902, quando Adrian Brown relatou uma investigação sobre a velocidade da hidrólise da sacarose pela invertase de levedura, demonstrando que quando a concentração de sacarose é muito maior do que a concentração da enzima, a velocidade da reação torna-se independente da sacarose, isto é, em relação à sacarose a reação é de ordem zero. Com isso, propôs que a reação enzimática global é composta por duas reações elementares, na qual o substrato forma um complexo com a enzima, e esse complexo se decompõe para o produto e a enzima.

Em 1913, Leonor Michaelis e Maud Menten propuseram um modelo para explicar essas características cinéticas, onde um complexo ES específico é um intermediário na catálise. Com isso podemos representar esquematicamente essa reação que consiste na formação de um complexo enzima-substrato ES, através da ligação reversível (representada pela seta dupla) de um substrato $S$ com uma enzima $E$, que em seguida reage irreversivelmente (representada pela seta única) para gerar um produto $\mathrm{P}$ e para regenerar a enzima livre $\mathrm{E}$.

As constantes $k_{1}, k_{-1}$ e $k_{2}$ representam as constantes cinéticas dessa reação, ou seja, $k_{1}$ e $k_{-1}$ as constantes de velocidade para as reações de formação e dissociação do complexo e $k_{2}$ uma constante de primeira ordem para a reação que converte o substrato em produto, sendo geralmente menor que as demais (MICHAELIS; MENTEN, 1913).

Esse processo pode ser representado pelo seguinte mecanismo:

$$
E+S \underset{k_{-1}}{\stackrel{k_{1}}{\rightleftarrows}} E S \stackrel{k_{2}}{\rightarrow} E+P
$$




\subsection{Modelagem}

$\mathrm{Na}$ modelagem matemática das reações dentro do mecanismo (1), obtemos as variações do substrato, da enzima, do complexo enzimático e do produto, através da aplicação da Lei de ação das massas de Lavoisier, onde a velocidade à qual uma reação química tem lugar, a uma dada temperatura, é diretamente proporcional ao produto das massas ativas dos reagentes, ou seja, nenhuma quantidade de massa é criada ou destruída em uma reação química.

Para descrever a variação da concentração de $\mathrm{E}$, no instante de tempo $t \geq 0$, podemos observar que ocorre uma variação da enzima devido à dissociação de uma dada concentração de complexo em $t$, como também, a variação das concentrações de E e S devido à formação do complexo. O raciocínio é análogo para definir as equações que descrevem as cinéticas das demais espécies.

Desse modo, representando essas concentrações por $S, E, C$ e $P$, respectivamente como substrato, enzima, complexo e produto, pode-se modelar o sistema de reação em (1) da seguinte forma (MURRAY, 2002):

$$
\begin{aligned}
& \frac{d S}{d t}=-k_{1} E S+k_{-1} C \\
& \frac{d E}{d t}=-k_{1} E S+k_{-1} C+k_{2} C \\
& \frac{d C}{d t}=k_{1} E S-k_{-1} C-k_{2} C \\
& \frac{d P}{d t}=k_{2} C
\end{aligned}
$$

Consideramos as seguintes condições iniciais:

$$
S(0)=S_{0}, \quad E(0)=E_{0}, \quad C(0)=0, \quad P(0)=0
$$

\subsection{Solução analítica do sistema}

Para o sistema de Equações Diferenciais não lineares obtido em (2) - (5) ser resolvido de forma analítica é necessário ser simplificado extraindo relações de conservação de massa referente as espécies químicas envolvidas na reação enzimática e admitindo uma hipótese de estado estacionário.

Contudo, podemos simplificar essas reações ao considerarmos a velocidade da reação em um tempo próximo de zero. Assim, como mostra o Gráfico 1, a velocidade de catálise $V_{0}$ foi determinada para cada concentração de substrato pela medição da velocidade de formação do produto em momentos anteriores ao acúmulo do produto (BERG; TYMOCZKO; STRYER, 2014). Nosso ponto de partida é que a velocidade de catálise é igual ao produto da concentração do complexo $C$ por $k_{2}$, logo temos: 


$$
V_{0}=k_{2} C
$$

Precisando expressar $C$ em termos de quantidades conhecidas, a velocidade de formação do complexo é dada por $C=k_{1} E S$ e a de degradação por $C=\left(k_{-1}+k_{2}\right) C$. Para simplificar o problema, George Briggs e John Haldane sugeriram, em 1924, a suposição do estado de equilíbrio dinâmico (BERG; TYMOCZKO; STRYER, 2014). Esse estado de equilíbrio é alcançado quando as velocidades de formação e degradação do complexo tornam-se iguais, mesmo se houver mudança nas concentrações dos materiais iniciais e dos produtos. Estabelecendo a igualdade

$$
k_{1} E S=\left(k_{-1}+k_{2}\right) C \rightarrow \frac{E S}{C}=\frac{k_{-1}+k_{2}}{k_{1}},
$$

obtemos a Constante de Michaelis $\left(K_{m}\right)$ :

$$
K_{m}=\frac{k_{-1}+k_{2}}{k_{1}}
$$

Podemos observar que $K_{m}$ tem as unidades de concentração e é a concentração de substrato na qual a velocidade da reação é metade da velocidade máxima, como no Gráfico 1. Dessa forma, se uma enzima tiver um $K_{m}$ pequeno, ela atinge o máximo de eficiência catalítica em baixas concentrações de substrato.

No mecanismo em (1) a enzima é um catalisador que apenas facilita acelerando o processo da reação. Considerando então a Lei de Conservação de Massas, onde uma relação de conservação entre reagentes e produtos é uma equação algébrica que relaciona uma concentração inicial dessas espécies químicas com seus respectivos valores em um dado tempo $t>0$, podemos reduzir o sistema adicionando as equações (3) e (4) junto com as condições (6), obtendo:

$$
\frac{d E}{d t}+\frac{d C}{d t}=0 \rightarrow E(t)+C(t)=E_{0} \quad \rightarrow \quad E(t)=E_{0}-C(t)
$$

Seguindo analogamente, podemos obter o substrato inicial, ao adicionarmos a concentração de substrato com o complexo e o produto, como segue abaixo:

$$
S_{0}=S(t)+C(t)+P(t) \rightarrow P(t)=S_{0}-C(t)-S(t)
$$

Por meio das curvas de progressão dos componentes da reação obtida por (SEGEL, 1975) (Figura 2), podemos observar que com exceção da base transitória da reação, que ocorre antes do bloco sombreado, as inclinações das curvas da progressão da enzima $[E]$ e do complexo $[E S]$ são essencialmente zero, desde que os substratos estejam em excesso em relação a enzima $(S \gg E)$. 
Gráfico 2: Curvas de progressão dos componentes da reação

Chart 2: Progression curves of the reaction components



Fonte: SEGEL, 1975.

Essa fase transitória, leva normalmente menos do que milissegundos para misturar à enzima e o substrato. Após essa fase o complexo $C$ permanece aproximadamente constante até que o substrato $S$ seja consumido. Portanto, durante a maior parte da reação, a velocidade de síntese do complexo deve ser igual a velocidade de seu consumo, mantendo-se em equilíbrio estacionário. Com isso, podemos supor que $C$ é constante:

$$
\frac{d C}{d t}=0
$$

Dessa forma, a velocidade de mudança de concentração do complexo é zero, o que nos permite igualar a zero a equação diferencial de $C$ :

$$
\frac{d C}{d t}=0=k_{1} E S-k_{-1} C-k_{2} C
$$

Aplicando a equação (10) na equação (13), obtemos:

$$
k_{1}\left(E_{0}-C\right) S-k_{-1} C-k_{2} C=0
$$

A resolução da equação (14), fornece:

$$
\frac{\left(k_{-1}+k_{2}\right) C}{k_{1}}=\left(E_{0}-C\right) S
$$

Considerando a Constante de Michaelis na equação (15), temos:

$$
K m C=\left(E_{0}-C\right) S \rightarrow C(t)=\frac{E_{0} S}{K m+S}
$$




$$
\begin{aligned}
& \text { Substituindo } E(t) \text { na concentração do substrato, equação (2), temos: } \\
& \frac{d S}{d t}=-k_{1}\left(E_{0}-C\right) S+k_{-1} C \rightarrow \frac{d S}{d t}=-k_{1} E_{0} S+C\left(k_{1} S+k_{-1}\right)
\end{aligned}
$$

Substituindo $C(t)$ na equação $(17)$, temos:

$$
\frac{d S}{d t}=-k_{1} E_{0} S+\frac{E_{0} S}{K m+S}\left(k_{1} S+k_{-1}\right)
$$

Implicando em:

$$
\frac{d S}{d t}=\frac{-k_{2} E_{0} S}{K m+S}
$$

Dessa forma, podemos reduzir o sistema (2) - (5) para um sistema com apenas uma equação diferencial, simplificando o modelo cinético da reação enzimática:

$$
\begin{gathered}
E(t)=E_{0}-C(t) \\
P(t)=S_{0}-C(t)-S(t) \\
C(t)=\frac{E_{0} S}{K m+S} \\
\frac{d S}{d t}=\frac{-k_{2} E_{0} S}{K m+S}
\end{gathered}
$$

Ao considerar que a enzima está presente em pequenas quantidades, a concentração do substrato efetivamente não se altera durante o estágio transitório inicial, logo a dinâmica do sistema é governada pela equação (23) com a condição inicial $S=S_{0}$. Resolvendo a EDO linear de Primeira Ordem pela técnica de Variáveis Separáveis, obtemos a solução implícita:

$$
\int \frac{K m+S}{-k_{2} E_{0} S}=\int d t \rightarrow K m \cdot \ln S(t)+S(t)=S_{0}+K m \cdot \ln S_{0}
$$

Com o substrato, podemos obter uma solução aproximada substituindo no sistema (20) - (23). Para isso, foi considerado valores para as constantes de velocidade de acordo com dados experimentais obtidos por Schnell e Maini (2002), considerando uma temperatura de $60^{\circ}$ e um $p H=6: 5$, como segue abaixo:

$$
k_{1}=9.4 \quad k_{-1}=8.1 \quad k_{2}=5
$$


Foram consideradas também as condições iniciais:

$S(0)=10, \quad E(0)=2.5, \quad C(0)=0, \quad P(0)=0$

O Gráfico 3 ilustra a curva do progresso dos participantes da reação, na qual o substrato muda consideravelmente e as inclinações das curvas da enzima e do complexo são nulas, referente a hipótese de estado estacionário que propomos.

Gráfico 3: Concentração das espécies obtida com a SoluçãoAnalítica do Sistema (20) - (23)

Chart 3: Concentration of the species obtained with the Analytical System Solution (20)-(23)

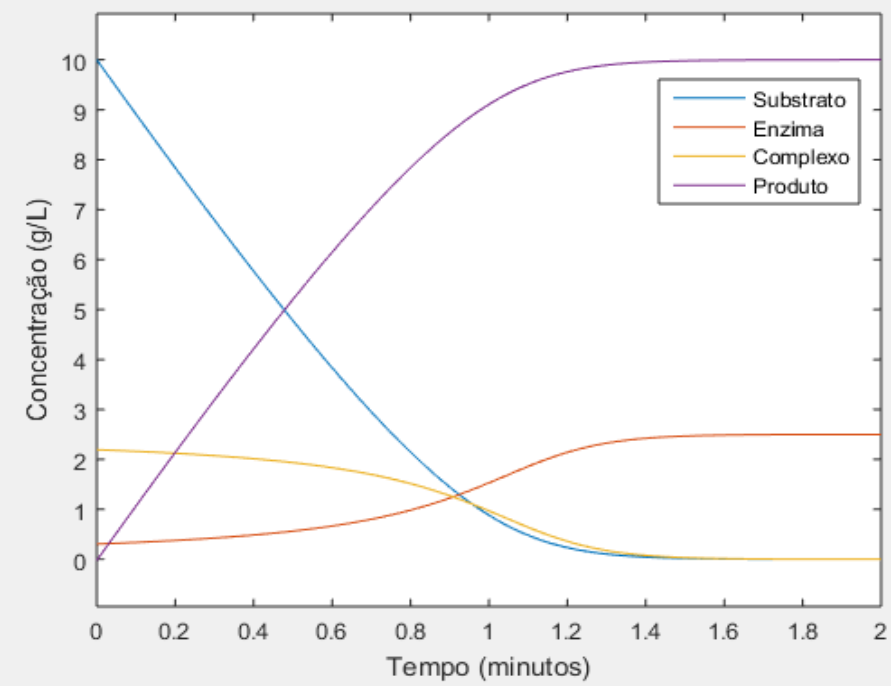

Fonte: Gráfico elaborado pelos autores.

Durante a segunda escala, o Gráfico 3 apresenta uma ótima aproximação para descrever o comportamento da concentração das espécies químicas envolvidas. Podemos observar que o produto possui um comportamento crescente enquanto o substrato decai, decorrente do fato do substrato ser transformado em produto e regenerado a enzima livre durante a reação, representando a quebra do amido para a formação dos açúcares.

\subsection{Solução numérica do sistema}

Utilizaremos o método numérico de Runge-Kutta Clássico de $4^{\mathrm{a}}$ ordem (RK4) para a obtenção de uma solução aproximada do sistema de equações diferenciais dado em (2) - (5). O método de Runge-Kutta Clássico de $4^{\mathrm{a}}$ ordem é um dos processos numéricos que apresenta boa precisão e uma zona de estabilidade maior. O algoritmo abaixo é reconhecido como uma ferramenta computacional valiosa, referido como o clássico método de Runge-Kutta (ZILL, 2016).

$$
\begin{gathered}
y_{n+1}=y_{n}+\frac{h}{6}\left(k_{1}+2 k_{2}+2 k_{3}+k_{4}\right) \\
k_{1}=f\left(x_{n}, y_{n}\right)
\end{gathered}
$$




$$
\begin{aligned}
& k_{2}=f\left(x_{n}+\frac{h}{2}, y_{n}+\frac{h}{2} k_{1}\right) \\
& k_{3}=f\left(x_{n}+\frac{h}{2}, y_{n}+\frac{h}{2} k_{2}\right) \\
& k_{4}=f\left(x_{n}+h, y_{n}+h k_{3}\right)
\end{aligned}
$$

Para resolver as equações diferenciais deste trabalho utilizamos o software Matlab, no qual foram inseridas rotinas de resoluções baseadas nas equações (27) - (31), referidas ao Runge-Kutta Clássico de $4^{a}$ ordem e considerando os valores (25) para constantes de velocidades e as condições iniciais (26), cujos resultados obtidos com RK4, observa-se no Gráfico 4.

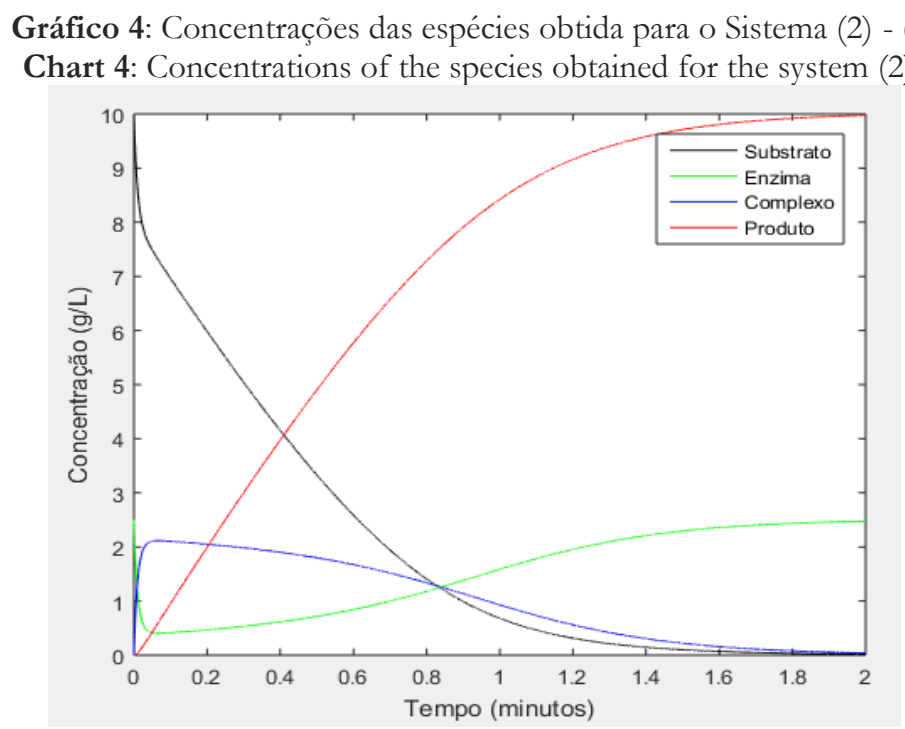

Fonte: Gráfico elaborado pelos autores.

\section{COMPARAÇÃO ENTRE OS RESULTADOS}

No desenvolvimento da solução analítica, supomos o estado estacionário para o complexo e consideramos que no estado transitório inicial da reação as inclinações das curvas de progressão da enzima e do complexo são essencialmente zero, desde que o substrato esteja em excesso em relação a enzima, simplificando assim, o modelo cinético da reação enzimática. Dessa forma podemos observar que o resultado analítico para muitas situações experimentais é suficiente, porém não sempre, por haver duas escalas de tempo envolvidas no sistema.

A primeira é a escala transitória inicial próxima de zero na qual a desconsideramos para fazer a simplificação do sistema de Equações Diferenciais não lineares, a segunda escala é quando o substrato muda consideravelmente e as inclinações das curvas da enzima e do complexo são nulas, referente à hipótese de estado estacionário que propomos. Durante a segunda escala, conforme já mostrado no Gráfico 3, apresenta uma ótima aproximação para descrever o comportamento da concentração das espécies químicas envolvidas.

Através da solução numérica obtida, pode-se observar que está de acordo com a atividade enzimática do mecanismo de Michaelis-Menten e com as curvas de progressão dos 
componentes da reação obtida por Segel, como mostra o Gráfico 2, onde o substrato apresenta uma decadência ao se unir com a enzima para a formação do complexo. Esse complexo apresenta um pequeno crescimento após a junção da enzima com o substrato, mas decai após reação de quebra para a formação do produto e liberação da enzima.

Podemos observar então que o produto possui um comportamento crescente enquanto o substrato decai, isso ocorre pelo fato do substrato ser transformado em produto durante a reação. Analisando o comportamento da enzima, podemos observar que ela sofre uma perda após se unir com o substrato, mas se recompõe com a formação do produto. Além disso, nessa solução podemos observar as duas escalas de tempo envolvidas.

Portanto os resultados apresentados, referentes a solução analítica e numérica, estão relacionados aos processos que envolvem a quebra de um determinado substrato (amido) para a formação de um produto (açúcares) através do processo de hidrólise, para então serem utilizados na produção do etanol. Podemos notar a importância da escala transitória inicial na reação ao compararmos o comportamento do substrato da solução numérica com a solução analítica, como mostra o Gráfico 5.

Gráfico 5: Relação entre o substrato e produto das soluções

Chart 5: Relation between substrate and product of solutions

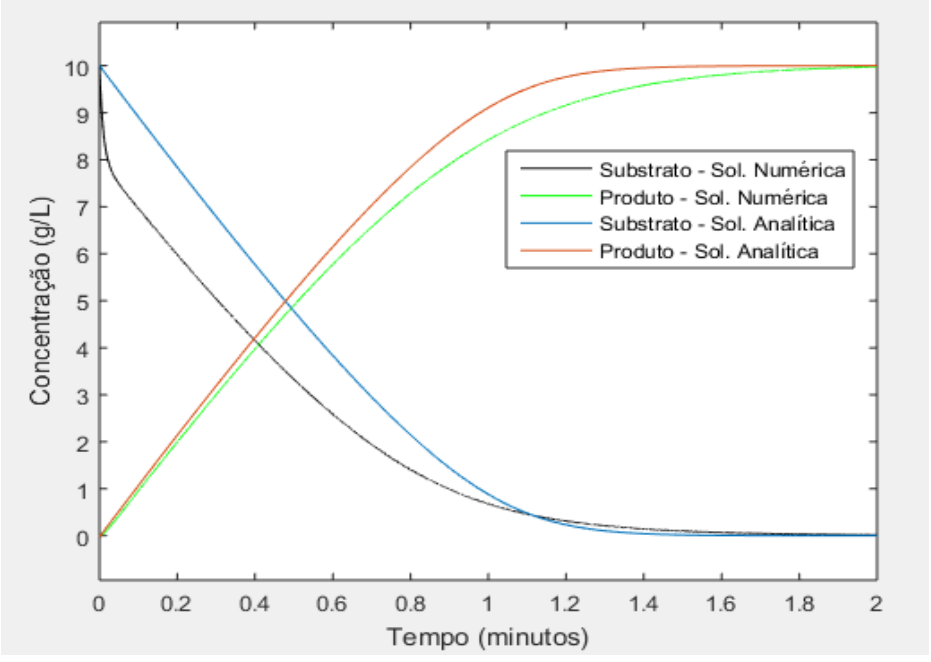

Fonte: Elaborado pelos autores.

Na produção de Bioetanol, utiliza-se plantas que são ricas em amido, como o milho, batatas, o arroz e a mandioca. No entanto, na produção do bioetanol utiliza-se o processo de hidrólise para quebrar as moléculas de amido em açúcares.

Os resultados obtidos neste trabalho descrevem como o processo de produção do bioetanol ocorre e, a partir de tais resultados, pode-se trabalhar na otimização da produção realizando melhores escolhas para o $\mathrm{pH}$ e temperatura, bem como, possíveis substitutos à enzima utilizada na reação.

\section{CONSIDERAÇÕES FINAIS}

A hidrólise enzimática apresenta vantagens em relação à sustentabilidade, apresentando um grande potencial em virtude de não possuir reações secundárias que poderiam levar à perda de rendimento e a formação de produtos secundários. Observa-se também que não 
requer altas temperaturas e pressões, evitando a quebra das moléculas da enzima.

A partir dos resultados obtidos por meio da solução numérica e analítica do modelo matemático desenvolvido, pode-se analisar o comportamento de cada concentração presente no processo de hidrólise enzimática, possibilitando a utilização e otimização desse processo na produção de Bioetanol.

\section{REFERÊNCIAS}

BERG, J. M.; TYMOCZKO, J. L.; STRYER, L. Bioquímica. 7.ed. Rio de Janeiro: Ed. Guanabara Koogan, 2014.

CRUZ, M.; GUERREIRO, E.; RAIHER, A. A Evolução da Produção de Etanol no Brasil, no Período de 1975 a 2009. Revista Econômica do Nordeste, Fortaleza, v. 43, n. 4, p. 142-143, 2012.

GOMES, R. S.; CARPES, C. Q.; LORENZZETTI, G. S.; BORTOLI, A. L. Modeling the hydrolysis process of the bioethanol production. Vetor, Rio Grande, v. 22, n. 2, p. 59-67, 2012. LOURENZANI, W.; BERNARDO, R.; CALDAS, M. Produção de biocombustível e alteração da composição agropecuária no Centro-Oeste do Brasil. Interações, Campo Grande, v. 17, n. 4, p. 562, 2016.

MICHAELIS, L.; MENTEN, M. M. L. The Kinetics of Invertase Action. Biochemische Zeitschrift, Vol. 49, p. 333-369, 1913.

MURRAY, J. D. Mathematical Biology: I. An introduction. 3rd ed. New York: SpringerVerlag, 2002. p. 175-178. (Interdisciplinary Applied Mathematics, Vol. 17).

PACHECO, T. F. Produção de Etanol: Primeira ou Seguda Geração?. Circular Técnica, 4, Brasília, p. 1-6, 2011.

SINGHANIA, R. R., PARAMESWARAN, B., PANDEY, A. Plant-Based Biofuels: An introduction. In: PANDEY, A. (Ed.). Handbook of Plant-Based Biofuels. Boca Raton: CRC Press, 2009, p. 3-12.

SCHNELL, S.; MAINI, P, K. Enzyme kinetics far from the standard quasi-steady-state and equilibrium approximations. Mathematical and Computer Modelling, Oxford, Vol. 35, p. 137-144, 2002.

SEGEL, I. H. Enzyme Kinetics: Behavior and Analysis of Rapid Equilibrium and SteadyState Enzyme Systems. New York: Wiley-Interscience, 1975.

ZILL, D. G. Equações diferenciais com aplicações em modelagem. Trad. 10.ed. Norte Americana por Márcio Koji Umezawa. São Paulo: Ed. Cengage Learning, 2016.

Artigo recebido: 25/07/2019.

Artigo aceito: 29/07/2019. 